\title{
Espacios públicos y privados. Construyendo diálogos en torno a la Economía solidaria
}

Public and Private Spaces. Building Dialogue around the Solidarity Economy Espaces publics et privés. Construisant des dialogues autor de l'économie solidaire

Jordi Estivill

\section{OpenEdition}

\section{Journals}

Edición electrónica

URL: http://journals.openedition.org/rccs/403

DOI: $10.4000 /$ rccs.403

ISSN: $2182-7435$

Editor

Centro de Estudos Sociais da Universidade de Coimbra

\section{Edición impresa}

Fecha de publicación: 1 marzo 2009

Paginación: 101-113

ISSN: 0254-1106

\section{Referencia electrónica}

Jordi Estivill, «Espacios públicos y privados. Construyendo diálogos en torno a la Economía solidaria », Revista Crítica de Ciências Sociais [En línea], 84 | 2009, Puesto en línea el 01 diciembre 2012, 


\section{Espacios públicos y privados. Construyendo diálogos en torno a la Economía solidaria}

La economía solidaria, concepto emergente e itinerante, necesita de diálogos que ayuden a delimitarlo y a precisar sus contenidos. En este artículo, tomando como referencia las aportaciones de Jean-Louis Laville, se reflexiona sobre los espacios económico, doméstico, mercantil, público y solidario. Proponemos también plantear que a partir de una revisión de la historia de la economía solidaria en los países periféricos y mediterráneos de Europa, se pone en evidencia un itinerario que no correspondería con el caso francés, sino que más bien se acercaría al latinoamericano.

Palabras clave: Economía solidaria y social, espacios públicos y privados, proyección política.

\section{La Economía Solidaria: un concepto emergente e itinerante}

Es de suponer que todo el mundo está de acuerdo que el concepto de economía solidaria ha nacido hace poco aunque la realidad, también hay que suponerlo, sea tan vieja como la humanidad. Esta novedad y el carácter emergente de esta noción la hacen relativamente más sensible a los debates que intentan definir sus contenidos. Por otro lado, su tierna edad invita a querer fijar sus contornos. Y ello tiene aun más riesgos cuando su nacimiento intelectual no deja de estar rodeado de algunas controversias al querer desmarcarse de la economía social, un concepto también sujeto a polémicas, aunque su historia escrita sea mas larga que la de la economía solidaria.

Además, nuestro emergente y joven concepto, poco después de haber nacido en la vieja Europa, ha empezado a viajar y ha atravesado el charco para ser adoptado en ciertos países de América Latina, especialmente en Brasil.

En este emergente e itinerante panorama, caben varios riesgos que se pueden señalar. El primero es que se quiera hacer una delimitación tan amplia de la economía solidaria que debajo de ella quepa todo o casi todo. O dicho de otro modo, que cualquier actividad ligada a la escasez que comporte una 
reciprocidad gratuita pueda ser incluida bajo este paraguas. El segundo riesgo es que se restringa mucho su definición, fijando fronteras precisas con criterios exigentes que pueden dejar fuera un buen número de experiencias que se encuentran a mitad de camino entre la economía social y la economía solidaria. En la fase actual, tanto la ampliación ilimitada del paraguas como la actuación aduanera, pueden ser negativas para la afirmación ascendente tanto de la práctica como de la teoría de la economía solidaria.

Un tercer riesgo consiste en que se quiera poner bajo el concepto de la economía solidaria situaciones internacionalmente tan alejadas que difícilmente pueden ser reconocibles, identificables y comparables como tales. ¿No es ésta, una de las críticas más sólidas a los esfuerzos, por otro lado meritorios, de la macro investigación comparativa lanzada por la Universidad Johns Hopkins sobre el tercer sector? La utilización de criterios etéreos y discutibles hace que, al final de la misma, casi nadie sepa qué tienen en común un hospital egipcio, una mutualidad alemana, una fundación americana, una universidad marroquí, una tienda de comercio justo israelí, una cooperativa social italiana, un proyecto de desarrollo comunitario en Quebec, una asociación de moradores de Brasil... Si bien es cierto que esta investigación ha puesto de relieve aspectos importantes del papel económico de un tercer sector que contribuye a la creación del producto interior y del empleo, es demasiado deudora de los esquemas y de la tradición norteamericanos de la filantropía civil y de la "Non Profit Economy". Hasta cierto punto ello le impide matizaciones que, en el caso de Europa, remiten a la utilización de otros criterios y a la cultura social y política de cada país. No se trata de preconizar una vuelta a los estudios que solo pueden ser interpretados a partir de las realidades "nacionales", pero sí de advertir que en las comparaciones transnacionales hay que ir con mucho cuidado de no proyectar sobre los otros la sombra del propio campanario.

No parece que estos riesgos estuvieron presentes en el seminario de Coimbra, pero el carácter incipiente, polifacético, itinerante y en construcción de la economía solidaria en algunos países, invita a ser prudente en la utilización de esta noción. De modo que Jean-Louis Laville calificó su intervención de hipótesis que permiten articular la democracia con la economía; Namorado habló de ámbito no estabilizado, de noción no univoca, de galaxias y constelaciones; Gaiger informó del reciente uso de la palabra en el Brasil, aun cuando en el interesante mapeamiento que presentó, se refirió a más de 21.000 iniciativas que podían situarse bajo el paraguas de la economía solidaria en el Brasil. Cattani explicó las dificultades con las que ésta se abre paso frente a una ideología dominada por el neoliberalismo. Al señalar, José Portela, la fraternidad, el poder y la participación como 
elementos constitutivos, invitaba a ir más allá de la contabilización y a fijarse en algunos de los valores oscilantes de la economía solidaria. Rogerio Amaro, después de afirmar que existe una cierta confusión entre economía social y solidaria, siendo la segunda hija de la primera, la caracterizó a partir de las experiencias de las Azores y de otras del resto de Portugal. Carlota Quintão puso en evidencia cómo las empresas de inserción en este país se abren paso, con dificultades, a partir de unos inicios basados en un esquema de arriba/abajo e inspirado en la situación francesa.

Así pues, las intervenciones del Seminario de Coimbra invitan a profundizar tanto en los aspectos teóricos de definición de la economía solidaria como en el mejor conocimiento de su realidad. Para hacerlo, se intenta, en esta limitada contribución, concentrar la atención en algunos puntos del potente esquema de Laville que, vistos desde una perspectiva ibérica, parecen más discutibles. Se trata de establecer un diálogo de crítica fraternal que abra pistas para avanzar hacia una interpretación más amplia de la economía solidaria.

\section{Las contribuciones de Laville}

No hay ninguna duda que las contribuciones de Laville han hecho progresar a la conceptualización de la economía solidaria en Europa. Desde la década de los años ochenta del siglo pasado, sus aportaciones fundamentadas en las propuestas de Polanyi y de Mauss han puesto en evidencia que, además de las formas dominantes de la economía mercantil guiada por el ánimo de lucro, existen una economía pública basada en la redistribución, una economía doméstica cuyo eje es la donación y "otra" economía articulada en torno a la solidaridad. La economía solidaria sería una hibridación de esta diversidad de economías que revitalizaría la democracia por cuanto supone nuevas formas de participación y de proyección política. De esta forma, la economía solidaria se distinguiría de la noción del tercer sector, más marcada por la acción privada de corte filantrópico y de la economía social que habría abandonado su dimensión política en el proceso de sucesivas diferenciaciones de sus diversas familias (cooperativas, mutualidades, asociaciones...) y por la institucionalización y su acomodación con el estado y el mercado.

La ofensiva neoliberal estaría rompiendo el equilibrio Keynesiano entre las dos últimas dimensiones y sacralizaría el principio del mercado como único autorregulador económico y privatizaría el espacio público. Frente a ello, se alzarían

una multitud de iniciativas que preconizan la adopción de comportamientos solidarios. En varios continentes, diferentes colectivos eclosionan en la agricultura biológica, 
el comercio justo, el consumo responsable, las energías renovables, el micro crédito, las monedas sociales, los servicios de proximidad, el turismo solidario... Ellos dibujan los contornos de una economía que se renueva con un proyecto de transformación a partir de compromisos ciudadanos. Lo que explica la implicación del movimiento alter mundialista en el reconocimiento de las iniciativas solidarias. (Laville, 2007:57)

Laville propone, además, una relectura de la historia según la cual la economía política pacifica a una sociedad que ha roto sus ataduras con el antiguo régimen, a través de la difusión del mercado, portador de los intereses personales y materiales. En el siglo XIX, la visión liberal piensa que el bien público es el producto de estos intereses y que su conjugación asegura la paz social y la democracia. No obstante, la pauperización y la degradación de las condiciones de vida y de trabajo, invalidan esta visión y generan una respuesta de las capas populares. Como afirma Laville,

la contradicción entre la libertad política y la sujeción económica se hace insoportable. Para muchos pensadores y obreros la confrontación con la miseria y la amplitud intolerable de las desigualdades les obliga a volverse hacia mecanismos de coordinación en las antípodas del interés. Así, la asociación, como ligazón social voluntaria entre ciudadanos libres e iguales, se afirma como otro principio de organización social. En contextos tan diferentes como América y Europa, las experiencias asociacionistas se multiplican, mezclando socorros mutuos, producción en común y reivindicaciones que reclaman una regulación política de la economía. (ibid.:44)

Aunque haya que esperar largo tiempo, son los poderes públicos los que van a materializar esta regulación correctora con la creación de la protección social y de otros mecanismos.

El valor de las aportaciones de Laville, nacidas en el contexto de la historia y la cultura política francesa, ha ultrapasado las fronteras del hexágono. En primer lugar, por sus colaboraciones con el grupo EMES ${ }^{1}$ y sus estudios comparativos europeos. En segundo lugar, extendiéndose hacia otros países francófonos como el Québec² y alargándose hacia las penínsulas Ibérica (Defourny et al., 1998) e Itálica (Laville y Gadin, 1997). En tercer lugar, abriendo un fecundo debate con América Latina $a^{3}$ y muy en especial con

\footnotetext{
${ }^{1}$ Una de sus colaboraciones se encuentra CIRIEC, 2000 (Caps. 5 y 6)

${ }^{2}$ Veanse las referencias a este autor en L'Observatoire de l'Economie Sociale, Développement Régional, Organisation Communautaire, del Québec.

${ }^{3}$ Ver sus dos colaboraciones en los dos numeros de la revista "Otra Economía ". Buenos Aires. RILESS
} 
el Brasil (França Filho y Laville, 2004). Jean-Louis Laville y sus colaboradores, entre los que destaca Bernard Eme, como muchos "militantes" de la economía solidaria, unen el esfuerzo de abrirse paso en el mundo de las ideas, con una voluntad de irradiación práctica. Así van tejiendo redes que van afirmando y dando a conocer los valores y las experiencias de la economía solidaria.

En el marco de esta irradiación y reconocimiento, puede ser útil hacerse algunas preguntas. ¿Existe hibridación de las diversas economías y cómo se refleja en el juego entre espacio público y espacio privado? ¿Hasta qué punto, las aportaciones de Laville son suficientemente generales y por lo tanto aplicables a todos los países? ¿En qué medida su visión histórica es deudora del propio itinerario francés y no hay que introducir algunas matizaciones que ayuden a reinterpretar la historia de una economía solidaria de una Europa periférica que quizás estaría más próxima de la latinoamericana?

\section{Espacios y territorios privados y públicos}

La coherencia del modelo que lleva a considerar que existen cuatro formas económicas comporta también la existencia de cuatro espacios reales y simbólicos: doméstico, mercantil, público y solidario.

La delimitación del primero es, a priori, fácil de establecer, ya que pasa fundamentalmente por la casa y sus alrededores. El trabajo a domicilio, la auto producción para el consumo, los intercambios monetarios o no con otras unidades familiares, el papel y el trabajo de la mujer en el mantenimiento y cuidado familiar serían sus modos más corrientes de producción e intercambio. La cosa se complica cuando, por un lado, se introduce la cercanía o lejanía de los huertos, la figura del obrero fabril a la vez jardinero, el pastoreo estacional, la provisión de primeras materias lejanas, la venta en los mercados locales, o por otro lado, cuando esta economía doméstica se nutre y se reproduce con las redes de vecindad, paisanaje, amistad y familias extensas. De alguna manera, ello invita a extender este territorio privado de proximidad. La calle, las plazas, los mercados locales y otros espacios intersticiales que podrían ser calificados de públicos, se ven inundados por una economía doméstica más o menos informal. Este tipo de economía es marginal en los actuales países del centro y del norte de Europa, pero sigue y de alguna forma se renueva en muchas de las zonas periféricas del viejo continente, en sus ciudades más importantes y ha sido y es la base económica más abundante de muchos países latinoamericanos. Muchas de las formas del micro empreendedorismo (Portela et al., 2008) encuentran sus raíces en esta base económica doméstica que se extiende y ramifica. 
Frente a ello, la pregunta que cabe formularse es la de hasta qué punto esta economía doméstica, familiar y local no ha sido el fundamento de una gran parte de la economía social y solidaria de la Europa mediterránea (Estivill, 1999) y constituye una de las características mas significativas de la economía popular suramericana (Coraggio, 1998 y 2007). Se trata de actividades económicas apoyadas en redes familiares y locales que permiten afrontar y resolver determinadas necesidades, crear trabajo, intercambiar bienes y servicios y sobrevivir. Se capitaliza sobre el trabajo, a menudo con la autoexplotación, y raramente consigue lucros consistentes. Puede ser paliativa e incluso opresiva y a veces emancipadora cuando se organiza y consigue acumular y repartir colectivamente, en una visión de transformación social. Entonces, intereses privados y generales pueden coincidir. Muy frecuentemente, la potencia pública la persigue (impuestos, organización del espacio,...), la tolera (porque queda desbordada) u organiza complicidades a su alrededor en su provecho particular.

El espacio público no se corresponde con la economía productiva del sector público, a menos que repensemos las ciudades como lugar productivo y distributivo de los intereses generales. No acostumbra a ser así. Y desde hace unos años, los sociólogos, antropólogos, geógrafos, arquitectos y urbanistas de todo el mundo, más bien están advirtiendo de la reducción del espacio público ciudadano. Se asiste a una privatización y mercantilización del mismo (Sennett, 1993). ¿No es ésta la alarma de Habermas (1992) cuando advierte de la clientelización del ciudadano? La misma advertencia proviene de México, cuando se afirma que "la conjunción de las tendencias desreguladoras y privatizadoras con la concentración transnacional de las empresas ha reducido las voces públicas" (García Canclini, 1995: 10).

No es posible aquí analizar detenidamente cómo se reorganizan las relaciones entre lo público y lo privado en las ciudades. Se trata simplemente de evocar que en esta relación de fuerzas en constante recomposición, la economía social y solidaria juega y tiene un papel a jugar. Tiene necesidades productivas, comerciales, sociales y culturales que, desde el espacio íntimo, próximo, se proyectan hacia el espacio colectivo, exterior. Ahora bien, delante de ello, puede dejarse comer este espacio entre una voraz iniciativa privada con ánimo de lucro, los centros comerciales en Portugal y España, y una planificación urbana que diseña la ciudad como vitrina de anticuario ${ }^{4}$. Si se somete a estas dos lógicas, entonces solo le quedan los espacios marginales, intersticiales. Perderlos seria aun más desastroso. $\mathrm{O}$, por lo contrario, puede contribuir a diseñar una ciudad más humana y sostenible, y

\footnotetext{
${ }^{4}$ Expresión tomada de Brandão (2005: 155).
} 
ocupar en abierta negociación con las autoridades locales y el resto de actores, los lugares que le convengan, donde el bien público se usa participadamente como un derecho de todos. De esta forma se conecta y se legitima, superando sus intereses propios, con los intereses generales, los cuales acostumbran a ser los menos generalizados de todos los intereses.

Pero el territorio público no se agota en la ciudad y tiene que ver con el patrimonio cultural y natural. En este sentido, la economía social y solidaria tiene amplias posibilidades de luchar contra el deterioro a que ambos se ven sometidos y demostrar que es capaz de crear las condiciones de un desarrollo socioeconómico respetuoso y promovedor de la cultura y del medio ambiente, que repercuta en favor de las gentes que viven en estos lugares.

\section{Revisitar la historia}

Laville nos invita a revisitar la historia. Bienvenida sea esta invitación porque conocer mejor el pasado de la economía social y solidaria es tener mejores armas para afrontar los problemas actuales y los desafíos futuros. La dificultad es que no hay una sola historia y que cuanto más se relee, más complejas se hacen sus interpretaciones. Queda aún mucho camino por delante para ser capaces de constituir una memoria europea de la economía solidaria.

De todos modos, una primera observación a establecer es que, si esta relectura se hace desde una cierta periferia europea, determinados espacios y sus relaciones entre ellos se iluminan de otra forma. Aparecen acentos y matizaciones específicos y de alguna manera significativos de otra mirada que no sigue necesariamente el itinerario marcado por Laville. ¿Cuáles son, sintéticamente, algunos de los trazos que caracterizan los orígenes y el desarrollo de la economía social y solidaria en la perspectiva de una Europa más periférica, más latina, más mediterránea?

La primera de las hipótesis sería la de la permanencia y solidez del llamado mundo agrícola y rural, en el que la producción familiar para el autoconsumo, los intercambios no monetarios, las relaciones sociales locales y la economía doméstica, son fundamentales. Además, los "sures" rurales de las tres penínsulas, Ibérica, Itálica y Griega (Papargeorgiu, 1998), pesan mucho en la historia económica, social y política de sus respectivos países. El latifundismo que condena a unas condiciones de supervivencia y a la emigración forzosa, el caciquismo que se ejerce despóticamente a escala local y unas reformas agrarias siempre esperadas pero que nunca llegan, hacen que el grito secular "la tierra para el que la trabaja" sea la principal bandera de las organizaciones campesinas, las cuales se ven duramente reprimidas por los grandes propietarios y por un estado lejano cuya capacidad de 
integración es mínima. Deben refugiarse a menudo en la clandestinidad y cuando emergen tienen enormes dificultades para crear y mantener espacios propios de organización y expresión que son a menudo defensivos. De todos modos, ocupaciones de tierras, colectividades agrarias, hermandades y ligas campesinas, casas del pueblo, sociedades de socorros mutuos, cajas cooperativas de crédito rural, celeiros comuns, mutualidades de seguro del ganado, propiedades colectivas de bosques y tierras baldías, salpican la historia de una economía social en la que queda mucho por descubrir.

Una de las consecuencias de estas dificultades de organización y expresión, es la radicalidad de las posiciones de las organizaciones populares del campesinado, que raramente adopta las formas asociativas y sindicales del proletariado industrial y urbano. La implantación y fuerza del anarquismo primero, y del socialismo libertario después, en Italia, España y Portugal' es una pista a seguir para explicar, en parte, el tipo de economía social que se origina en estos países.

En cualquier caso, muchos de los autores decimonónicos que la defienden introducen la presencia y potencia de un mundo rural y familiar, basado en mecanismos informales ${ }^{6}$, que diferenciaría a estos países con respecto a las formas de la economía social del centro y norte de Europa.

Uno de los pioneros de la economía social portuguesa, Alexandre Herculano, en 1844, en su clásico texto "Das Caixas Económicas”, se debate en la contradicción de un Portugal "nación esencialmente agrícola, la industria manufacturera nos parece que nunca llegará a desequilibrarse con la agricultura" y donde "el hombre trabajador, sin embargo, no cuenta con obreros, porque el obrero es él, lo es su mujer, lo son sus hijos, cuyo trabajo valdrá el doble del de los trabajadores asalariados del rico" (Herculano, 1844: 55).

En su texto, trata explícitamente de distanciarse de los modelos de las Cajas Económicas francesas y británicas, de las que es deudor en su aprendizaje, cuando afirma, aventuradamente: "la suerte de los trabajadores rurales portugueses es, sin lugar a dudas, más feliz que la de los ingleses, e igual a la de aquellos de cualquier otro país de Europa, con la excepción de la Toscana" (ibid: 55). ¿Visión idílica de una Toscana rural y arcadiana? Lo importante a señalar, es la manifestación de una especificidad portuguesa de la economía social que se fundaría en la familia y la agricultura.

La segunda hipótesis, complementaria y en cierto modo contradictoria, consistiría en que las iniciativas de la economía social de estos países se

\footnotetext{
${ }^{5}$ En el caso de Portugal, quizás haya que rehacer una relectura del Azoreño Antero de Quental y de sus propuestas Proudonianas y federalistas.

${ }^{6}$ La defensa de esta diferenciación llega hasta nuestros dias. Ver Coutinho (2003:130).
} 
originan, crecen y se desarrollan más en sus respectivos nortes, donde hay una mayor industrialización y urbanización. Al mismo tiempo, se constata que muchas de estas iniciativas van entrelazadas con gremios y corporaciones que tienen una fuerza y sobre todo persistencias mayores que en algunos de los países centrales. Si ello es cierto, ¿una clave para entenderlo no sería la lentitud y debilidades de las revoluciones burguesas y los límites a la implantación de la hegemonía del mercado, en el siglo diecinueve en estos países? Quizás por esto algunos autores portugueses establecen unas fases en las que, siguiendo las clásicas distinciones de Gide, la primera de ellas seria la del solidarismo.

En cualquier caso estas iniciativas tienen una dimensión local y urbana importante y en ellas participan los grupos más cualificados y alfabetizados de la clase obrera y de la pequeña burguesía ciudadana (artesanos, comerciantes, funcionarios, artistas). Las fórmulas cooperativas, asociativas y mutuales no solo ofrecen respuestas a las necesidades económicas más perentorias, sino que frecuentemente, promocionan experiencias socioculturales (ateneos, sociedades culturales, escuelas, orfeones y bandas de música, centros enciclopedistas, teatrales y recreativos, casinos populares...). Son una respuesta colectiva a intereses particulares pero que tienen una proyección pública que a menudo es notoria a escala local, en las ciudades intermedias y grandes. Sus modos de organización democratizante no dejan de ser una alternativa frente a los modelos dominantes de la época y de su entorno. Así en Portugal, también en España e Italia, el derecho de asociación, en la que se aplica el principio democrático de "una voz, un voto", se convierte en una de las principales y pioneras reivindicaciones, que no dejará de estar presente durante mucho tiempo.

A lo mejor es en el papel histórico de la economía social a escala local, donde se encuentra una explicación al hecho de ser en estos países donde mayor eco e implantación ha tenido el desarrollo territorial de base local desde los años ochenta del siglo anterior (Estivill, 2008). Y también quizás por ello, es mayor la ligazón entre el desarrollo local y la economía social y solidaria (Demoustier, 2004). Dicho de otro modo, a este tipo de experiencias les es más fácil salir del propio cascarón de la defensa de los intereses de sus miembros para articularse con los procesos de desarrollo socioeconómico y medioambiental cuando se insertan y defienden una fuerte identidad territorial ${ }^{7}$ y se alían con los actores locales.

\footnotetext{
${ }^{7}$ En este punto seria interesante una comparación con el Québec. Esta fuerte identidad territorial es sin duda una de las explicaciónes del caso de Mondragón y podría también constituir una de las razones de ser de la especificidad de la economía solidaria de las Azores. Ver Amaro y Madelino (2004).
} 
La tercera hipótesis distintiva concerniría al papel del estado. Anacrónico, que se moderniza muy lentamente, despótico, con largos periodos dictatoriales que llegan hasta bien entrado el siglo veinte, mediatizado por sus clientelas seculares, estructura con pocos medios a la beneficencia pública, permitiendo, entre otras cosas, que la Iglesia continúe teniendo un poder enorme de intervención social, educativa y sanitaria. En estas condiciones, una gran parte de la economía social es casi necesariamente asistencial y se articula con las instituciones privadas y eclesiásticas. Solo pequeños sectores de la burguesía "ilustrada", y en general republicana y laicizante ${ }^{8}$, patrocina y respalda las iniciativas de la economía social. Otra parte de la burguesía mas industrial o bancaria, prefiere crear sus propias instituciones que protegen y controlan (colonias industriales, economatos, escuelas profesionales y empresariales...) a "sus" trabajadores.

No deja de ser interesante la mirada de un argentino que, a inicios del siglo veinte, visita la economía social de algunos países del viejo continente. Castillo, así se llama, jurista y consultor de las sociedades mutuales de su país, publica un libro (Del Castillo, 1913) que es el resultado de la misión encomendada por la "Mutualité" francesa, con el objetivo de "marcar nuevos rumbos a la acción mutualista en 'Sud America', de acuerdo con el adelanto alcanzado por las instituciones similares de Europa". Su panorama de las organizaciones mutuales, cooperativas y de las medidas de previsión social de Alemania, Bélgica, España, Francia, Inglaterra e Italia es riguroso. Incluso cita las bodegas cooperativas y el decreto de 17 de Julio de 1886 que establecía la caja de retiros para los obreros de los establecimientos estatales y los funcionarios de Portugal. Les dedica elogiosos comentarios y trata de ver sus posibilidades de adaptación en América Latina. Su visión es que la intervención del estado y el amparo de la ley son beneficiosos por cuanto suponen una garantía para los derechos de los miembros de estos organismos y una ayuda financiera y fiscal a los mismos.

Pero no deja de ser curioso y hasta cierto punto paradójico que, con su tesis en favor de la intervención pública, a la hora de proponer un modelo, se incline por el italiano. Primero, por su similitud (ibid.: 16) con las mutualidades argentinas. De estas, unas 559 con 207.550 socios, 260 son originadas por los inmigrantes italianos, 146 por los españoles, 81 por los franceses. Solo 47 serian puramente argentinas. Segundo, porque cuando comenta la

\footnotetext{
${ }^{8}$ En los estudios históricos sobre el origen y desarrollo de la economía social en Cataluña, cada vez esta más claro el papel de la francmasonería.
} 
ley italiana de Sociedades de Socorros Mutuos de 15 de Abril de 1886 avanza su posibilidad de no reconocimiento gubernamental ${ }^{9}$, afirmando que

con todo, las sociedades Italianas de Socorros mutuos se muestran refractarias a la tutela del gobierno, prefiriendo la mas absoluta autonomía, que les deja en completa libertad de acción, en la que ellos conceptúan una asociación voluntaria de mutua ayuda y consenso, en cuyas disposiciones el consejo gubernativo poco podría contribuir a su mayor prosperidad. (ibid.: 28)

Quizás la tercera razón estriba en la constatación que hace de las sociedades de socorros mutuos italianas porque además de la cobertura sanitaria construyen casas para obreros, dan un subsidio familiar a los asociados que tengan que hacer el servicio militar, dan dotes a los hijos, procuran trabajo a los afiliados, fundan bibliotecas sociales y crean escuelas para los hijos de los afiliados y nocturnas para estos. Es decir, están cubriendo un conjunto de necesidades y creando un mundo autónomo y "refractario a la tutela del gobierno". Por fin, y no deja de ser divertido, Castillo apunta que las mutualidades argentinas

están, por el momento, organizadas con fines limitadísimos...siendo el fin primordial el del vinculo entre sus asociados, procurando a sus familias esas reuniones periódicas, en las que se consagran unas útiles horas a la difusión del arte y a los placeres de la danza en las reuniones familiares que en sus espaciosos locales celebran con relativa frecuencia. En esto se puede señalar que aquellas asociaciones han contribuido en gran parte a la cultura popular, tanto de Buenos Aires como del resto de la Republica. (ibid.: 48 y 49)

No se encontraría aquí, en la contribución a la cultura popular, otro punto común entre la economía social y solidaria latinoamericana y la de los países periféricos y del sur de Europa. De esta lúcida manera, lo valora Ferreira da Costa, cuando explica los trazos comunes de los reformadores portugueses del siglo XIX:

De la tentación de simplificar lo complicado se libraron nuestros reformadores: en vez de una teoría del Estado, uno y vertical, intentaron entender a los pueblos en sus diversas y policéntricas afinidades naturales. Considerando deseable la iniciativa popular descentralizada, reconocieron claramente el valor de las culturas periféricas e de su expresión multiforme. (Ferreira da Costa. 1991:61)

$\overline{9}$ Dice nuestro autor que de unas 7.000 sociedades solo 2000 habían sido reconocidas. 
En estos países, los mecanismos públicos de protección laboral y social se instalan $\operatorname{tarde}^{10}$, son muy selectivos y se completan en periodos dictatoriales en los que se reprime duramente a las organizaciones populares. Las bases de la Seguridad Social recibieron un impulso en 1935 en plena dictadura de Salazar, un año antes en Grecia (IKA) con Metaxas, y en 1964 con Franco. Todas estas dictaduras, incluida la de Mussolini, trataron de integrar política y socialmente a los trabajadores creando una multitud de mecanismos desde la casa al trabajo y pasando por el ocio. A pesar de ello, en la historia de estos países, el palo ha ganado casi siempre a la zanahoria. El concepto y la práctica de la ciudadanía, con el ejercicio y la conciencia de los derechos, no toman carta de naturaleza masiva hasta bien entrado el siglo veinte.

Por todas estas razones, la historia de la economía social es política en el sentido amplio de la palabra. Ello no significa desconocer las expresiones de apoliticismo formal, manifestado en los principios cooperativos, en asociaciones culturales, en sociedades mutuales (Ferreira da Costa, 1991). A menudo, éstas son manifestaciones de refugio frente a la represión, y de desconfianza frente a la intervención pública y la acción política partidaria y convencional, al mismo tiempo que sugieren un discurso diferente frente al de la sociedad que les domina. Sus posibles ambigüedades provienen más del tipo de realizaciones prácticas en la búsqueda, renovada y contradictoria, de un espacio autónomo entre el mercado y el estado. En esta búsqueda, nadie, ni la economía social ni la solidaria, pueden tener el monopolio de la renovación democrática. Ambas comparten dinámicas más o menos participativas y un discurso político que se sitúa, por ahora, en la perspectiva de la reforma social. El futuro dirá si los crecientes antagonismos con el orden establecido y la afirmación de la propia vía, les llevará por otros caminos más alternativos.

\section{Bibliografía}

Amaro, R. Roque; Madelino, Francisco (2004), Contributos para um conceito. Economia solidária. Madeira: Projecto Cores.

Brandão, Pedro (2005), “Apocalípticos integrados. Notas de 'pensamento paralelo' sobre o espaço público e economia”, Cadernos Edifícios do Laboratório Nacional de Engenharia Civil, 64.

CIRIEC (2000), Les entreprises et organisations du troisième système: Un enjeu stratégique pour l'emploi. Bruxelles: CIRIEC.

\footnotetext{
${ }_{10}$ Ver a este respecto la cronología que se presenta en Estivill (2000).
} 
Coraggio, José Luís (1998), Economía popular urbana: Una nueva perspectiva para el desarrollo local. Buenos Aires: ICO-UNGS.

Coraggio, José Luís (org.) (2007), La economía social desde la periferia. Contribuciones Latinoamericanas. Buenos Aires: UNGS.

Coutinho, Manuela (2003), Economia social em Portugal. Lisboa: PIHTS-APPS.

Defourny, Jacques; Favreau, Louis; Laville, Jean-Louis (orgs.) (1998), Inserción y nueva economía social. Un balance internacional. Madrid: Ministerio de Trabajo.

Del Castillo, Benjamin E. (1913), Mutualidad, Cooperativismo y Previsión. Valencia: F. Sempere y Compañía Editores.

Demoustier, Danièle (org.) (2004), “Economie Sociale et Développement Local”, Les Cabiers de l'Economie Sociale, 3.

Estivill, Jordi (1999), Una via Mediterranea della economia sociale. Alcune chiave interpretative. Bolonia: Fondazione Cesar.

Estivill, Jordi (2000), "A View From the South: Different Colours for a Single European Jigsaw Puzzle”, in AA.VV., Policies and Instruments to Fight Poverty in the European Union. Almansil / Lisboa: Ministério de Trabalho e da Solidariedade.

Estivill, Jordi (2008), Desenvolvimento local e protecção social na Europa. Genebra: STEP-OIT.

Ferreira da Costa, Fernando (1991), Contributo português na ideação de uma economia social. Lisboa: INSCOOP.

França Filho, Genauto C.; Laville, Jean-Louis (2004), Economia solidária. Uma abordagem internacional. Porto Alegre: Editora da UFGRS.

Garcia Canclini, Nestor (1995), Consumidores y ciudadanos: Conflictos multiculturales de la globalización. Méjico: Grijalbo.

Habermas, Jürgen (1992), “L'espace public, 30 ans après?”, Quaderni, 18, 173-184.

Herculano, Alexandre (1844), Das Caixas Económicas. Reprod. in Opúsculos Tomo I, Lisboa: Livraria Bertrand.

Laville, Jean-Louis (2007), "Du XIX au XX siècle: Permanence et transformations de l'économie solidaire”, ECOSOL Review, 1.

Laville, Jean-Louis; Gardin, Laurent (1997), "L'impresa sociale. Una nuova realtá”, Rev. Impresa Sociale, 32, 20-30.

Papageorgiou, C. L. (1998), The Role of Social Economy and Its Dimension in Greece. Bolonia: Fondazione Cesar.

Portela, José; Hespanha, Pedro; Nogueira, Clãudia; Teixeira, M. Sérgio; Baptista, Alberto (2008), Microempreendedorismo em Portugal. Lisboa: POEFDS-INSCOOP.

Sennet, Richard (1993), A decadência do homem público. As tiranias da intimidade. São Paulo: Companhia de Letras. 